\section{SJS/TENN: A Mnemonic for Early Clinical Diagnosis of Stevens-Johnson Syndrome and Toxic Epidermal Necrolysis}

Brett C. Neill, M.D., Edward W. Seger, M.D., M.S., Jessica E. Ferguson, B.S., Tyler Hooton, M.D., Jace J. Rickstrew, B.S., M.D., Anand Rajpara, M.D. University of Kansas Medical Center, Kansas City, KS Department of Internal Medicine, Division of Dermatology Received Nov. 23, 2020; Accepted for publication.Jan. 28, 2021; Published online April 19, 2021 https: doi.org 10.17161 kjm.voll414842

\section{INTRODUCTION}

Stevens-Johnson Syndrome (SJS) and toxic epidermal necrolysis (TEN) represent a spectrum of the same condition defined by its widespread skin and mucosal loss. ${ }^{1}$ SJS/TEN represents a true dermatologic emergency, as the disease quickly evolves and is often fatal without early identification and treatment. It is essential for all clinicians to be familiar with common signs associated with SJS/TEN, as patients are more likely to present initially to primary care providers and emergency physicians than they are to a dermatologist. Certain characteristics of SJS/TEN allow it to be distinguished from common mimickers such as Drug Rash with Eosinophilia and Systemic Symptoms (DRESS), Erythema Multiforme (EM), and morbilliform drug reactions. ${ }^{1}$ We present the "SJS/TENN" mnemonic of clinical characteristics to aid in the early diagnosis for suspected cases (Table 1).

\section{S.JS/TENN - A Mnemonic for Improving Accuracy of Clinical Diagnosis}

Systemic Symptoms. A prodrome of symptoms, including fever greater than $39^{\circ} \mathrm{C}$, general malaise, sore throat, and cough with onset of days prior to cutaneous manifestations. Approximately 63 - $65 \%$ of SJS/TEN cases presented with history of fever, ${ }^{1,2}$ with rates increasing to $91 \%$ when ocular involvement was present at time of presentation. ${ }^{8}$ By comparison, 33 - 44\% of patients with DRESS presented with fever, and even lower rates were found in EM and morbilliform drug eruptions. ${ }^{1,2}$ Similarly, general malaise was documented in $55 \%$ of SJS/TEN

\section{KANSAS JOURNAL of MEDICINE}

cases, compared with $19 \%$ of DRESS cases.

Jarring Pain. Skin tenderness was found in up to $90 \%$ of patients, related to the onset of blistering and erosions. ${ }^{1}$ This may be present before skin loss and ulceration is observed. By comparison, skin tenderness was observed with $29 \%$ of patients with DRESS and $31 \%$ with acute generalized exanthematous pustulosis, another common mimicker. $^{1}$

Surfaces Mucosal. Involvement of skin, as well as mucosal surfaces, is a hallmark of SJS/TEN. Particular consideration for SJS/ TEN should be given if oral (mucosal ulcerations and erosions), ocular (conjunctival injection, desquamation of eyelid skin, and corneal ulceration), or genital (vulva ulceration and desquamation of scrotum or glans penis) involvement is noted. Oral involvement was present in 7l - 94\% of cases, ocular involvement in 57 - 100\% of cases, and genital involvement in $11-63 \%$ of cases. ${ }^{2-8}$

Targets Atypical. Flat or elevated targetoid lesions with poorly defined boarders and with or without bulla/erosion, which are present in two distinct skin zones, raises suspicion for SJS/TEN. ${ }^{1}$ A macule with a central dusky violaceous hue ("dusky macule") also is considered an atypical lesion. These atypical lesions were present in $65 \%$ of SJS/TEN cases, compared with $5 \%$ of DRESS and $13 \%$ of EM cases. ${ }^{1,2}$

ENT. Otolaryngologic complaints often are seen, including odynophagia, dysphagia, nasal obstruction, and otalgia. Ninety-eight percent of patients evaluated by an Ear-Nose-Throat (ENT) specialist had otolaryngologic involvement during the acute phase (with $94 \%$ in the oral cavity, lips, buccal mucosa, and gum). ${ }^{2}$ Importantly, a presentation of dyspnea or dysphonia was associated with a severe ENT form of disease characterized by supraglottic and laryngeal lesions (due to the risk for upper airway obstruction).

Table 1. Prevalence of clinical findings included in SJS/TENN mnemonic.

\begin{tabular}{|c|c|c|c|c|c|c|c|c|c|}
\hline $\begin{array}{l}\text { Clinical } \\
\text { finding }\end{array}$ & $\begin{array}{l}\text { Bequignonetal. }^{2} \\
2015\end{array}$ & $\begin{array}{c}\text { Jeunget al. }^{3} \\
2010\end{array}$ & $\begin{array}{c}\text { Kamaliah et al. }^{4} \\
1998\end{array}$ & $\begin{array}{l}\text { Kimetal. }^{5} \\
2012\end{array}$ & $\begin{array}{c}\text { Rajaratnam et al. }^{6} \\
2010\end{array}$ & $\begin{array}{c}\text { Revuz et al. } \\
1987\end{array}$ & $\begin{array}{c}\text { Sotozono et al. }^{8} \\
2009\end{array}$ & $\begin{array}{c}\text { Weinkle et al. }^{1} \\
2019\end{array}$ & $\begin{array}{c}\text { Yamane et al. } \\
2015\end{array}$ \\
\hline $\begin{array}{l}\text { Systemic } \\
\text { symptoms }\end{array}$ & - & $65 \%$ & $62 \%^{\mathrm{a}}$ & $60 \%$ & $62 \%$ & & $91 \%$ & $63 \%$ & - \\
\hline $\begin{array}{l}\text { Jarring } \\
\text { pain }\end{array}$ & - & - & - & $42 \%$ & $76 \%$ & & - & $90 \%$ & - \\
\hline \multicolumn{10}{|l|}{$\begin{array}{l}\text { Surfaces } \\
\text { mucosal }\end{array}$} \\
\hline Oral & $94 \%$ & $90 \%$ & - & $85 \%$ & $71 \%$ & 93.1 & $87 \%$ & - & $79 \%$ \\
\hline Ocular & - & $90 \%$ & - & $60 \%$ & $57 \%$ & 78.2 & $100 \%$ & - & $64 \%$ \\
\hline Genital & - & $11 \%$ & - & $33 \%$ & $57 \%$ & 63.2 & $49 \%$ & - & $41 \%$ \\
\hline $\begin{array}{l}\text { Targets } \\
\text { atypical }\end{array}$ & - & - & - & - & - & & - & $64 \%$ & - \\
\hline $\begin{array}{l}\text { ENT } \\
\text { symptoms }\end{array}$ & $98 \%$ & 90 & - & 85 & $71 \%$ & & $87 \%$ & - & $79 \%$ \\
\hline New drug & $84 \%$ & $100 \%$ & $88 \%$ & $52 \%$ & $95 \%$ & & $89 \%$ & $97 \%$ & $72 \%$ \\
\hline $\begin{array}{l}\text { Nikolsky } \\
\text { sign }\end{array}$ & - & - & - & - & $86 \%$ & & - & - & - \\
\hline
\end{tabular}

aPercentage of cases reported for a combined cohort of SJS/TEN $(n=25)$ and EM $(n=4)$. 


\section{KANSAS JOURNAL of MEDICINE} SJS/TENN

continued.

New Drug. Clinical suspicion for SJS/TEN immediately should prompt a thorough medication review, as nearly all cases are triggered by new drug exposure within the past 4 - 28 days. ${ }^{4,6,9,10}$ The list of culprit medications is vast; however, commonly implicated drugs include antibiotics (particularly ones containing sulfonamide), antiepileptics (such as lamotrigine and phenytoin), and allopurinol.

Nikolsky Sign. This sign is defined by sloughing of the skin induced by applying firm sliding tangential pressure. It is not specific to SJS/ TEN and is seen in other conditions, such as staphylococcus scalded skin syndrome and pemphigus vulgaris; however, its presence helps to distinguish SJS/TEN from EM and morbilliform drug eruptions (where it would be absent).

Systemic symptoms preceding onset of skin and mucosal lesions, particularly if these lesions are painful and present with pressure induced skin sloughing (indicating a positive Nikolsky sign), are all suggestive of potential SJS/TEN. Additional signs, such as dyspnea and dysphagia, may point to a more severe ENT form with an increased risk for upper airway obstruction. Prompt identification and onset of treatment is essential and can be lifesaving with SJS/TEN; therefore, this proposed mnemonic will provide particular utility to clinicians who are infrequently exposed to this condition and its acute signs and symptoms.

\section{REFERENCES}

${ }^{1}$ Weinkle A, Pettit C, Jani A, et al. Distinguishing Stevens-Johnson Syndrome/toxic epidermal necrolysis from clinical mimickers during inpatient dermatologic consultation - A retrospective chart review. J Am Acad Dermatol 2019; 81(3):749-757. PMID: 31150704.

${ }^{2}$ Bequignon E, Duong TA, Sbidian E, et al. Stevens-Johnson Syndrome and toxic epidermal necrolysis: Ear, nose, and throat description at acute stage and after remission. JAMA Dermatol 2015; 151(3):302-307. PMID: 25671761.

3 Jeung YJ, Lee JY, Oh MJ, Choi DC, Lee BJ. Comparison of the causes and clinical features of drug rash with eosinophilia and systemic symptoms and Stevens-Johnson Syndrome. Allergy Asthma Immunol Res 2010; 2(2):123126. PMID: 20358026

${ }^{4}$ Kamaliah MD, Zainal D, Mokhtar N, Nazmi N. Erythema multiforme, Stevens-Johnson Syndrome and toxic epidermal necrolysis in northeastern Malaysia. Int J Dermatol 1998; 37(7):520-523. PMID: 9679693.

${ }^{5}$ Kim HI, Kim SW, Park GY, et al. Causes and treatment outcomes of Stevens-Johnson Syndrome and toxic epidermal necrolysis in 82 adult patients. Korean J Intern Med 2012; 27(2):203-210. PMID: 22707893.

${ }_{6}^{6}$ Rajaratnam R, Mann C, Balasubramaniam P, et al. Toxic epidermal necrolysis: Retrospective analysis of 21 consecutive cases managed at a tertiary centre. Clin Exp Dermatol 2010; 35(8):853-862. PMID: 20456393.

7 Revuz J, Penso D, Roujeau JC, et al. Toxic epidermal necrolysis. Clinical findings and prognosis factors in 87 patients. Arch Dermatol 1987; 123(9):1160-1165. PMID: 3632000.

8 Sotozono C, Ueta M, Koizumi N, et al. Diagnosis and treatment of Stevens-Johnson Syndrome and toxic epidermal necrolysis with ocular complications. Ophthalmology 2009; 116(4):685-690. PMID: 19243825.

9 Yamane Y, Matsukura S, Watanabe Y, et al. Retrospective analysis of Stevens-Johnson Syndrome and toxic epidermal necrolysis in 87 Japanese patients--Treatment and outcome. Allergol Int 2016; 65(1):74-81. PMID: 26666483

${ }^{10}$ Maverakis E, Wang EA, Shinkai K, et al. Stevens-Johnson Syndrome and toxic epidermal necrolysis standard reporting and evaluation guidelines: Results of a National Institutes of Health Working Group. JAMA Dermatol 2017; 153(6):587-592. PMID: 28296986.

Keywords: Stevens-Johnson Syndrome, toxic epidermal necrolysis, dermatology, adverse drug reaction 